\title{
Portals and University Libraries
}

\section{The promise of libraries}

Libraries are places of contradiction. The library many of us still think of when we use the word - the building or place filled with mostly printed material - invites its users to find or ask for an item of recorded knowledge by which they may be informed for their improvement or their harmless entertainment. The invitation has behind it a thrilling and inspiring assumption: that the work of humankind should be freely available for all to share, and that the places for sharing it should be found within every town or city, and essentially within every place of learning. Nevertheless, this free use of our collective intellectual resource is not really free at all. As contributors to our societies, we pay for the service through taxation, and in doing so, we pay for a service based on a distribution ratio of one resource to many users. The use of the resource is therefore constrained by demand, and time-limited. If we breach that condition, we pay a fine, or a replacement item charge. And if we want an item which is not held by our local library, we may well have to pay a charge for the administrative effort of using our library as a user of some larger library somewhere else. The assumption behind the existence of libraries is thrilling and inspiring indeed, but the reality of service is inevitably compromised so that the freedom which they deliver is of course only a limited freedom.

Nonetheless, people love libraries because they witness to something generous in our collective spirit: like free health care and free basic education, they acknowledge our duty to each other. What sets them apart from health care and education, and other social services, indeed, is that their usage is optional. Alongside museums and galleries, they belong to the category of use we call 'culture'. They exist in their purest form as public libraries. The libraries we are concerned about here, academic libraries, are less pure because their use is mandated for the students, researchers and staff they serve for which they provide a collective resource pool. Nonetheless, they still behave with the altruism we are used to from using public libraries: they treat requests for material seriously, and they rarely say 'no' to a request. They also function as back-up libraries for the use of the public, and the current political climate in the UK encourages them to respond positively to this broader role, as universities themselves open their doors more widely to the general public, transforming their role as symbols of learning within communities into one which is genuinely functional.

University libraries now, like all publicly funded libraries, need to consider their users as sets arranged in concentric rings. Their duty lies in serving their immediate circle of users - staff and students of the institution - first and foremost. Once that need is met, however, they also need to provide ways to serve the users in the further rings, albeit with more restricted services, or with charges applied for service. Often, however, libraries must say 'wait', and the solemn act of waiting may seem an appropriate act of homage to the privileged act of learning from great minds. Users in the inner circle should have the least waiting to do, since their need of access to great minds is the most urgent, as recognised by their membership of the university. 
So libraries promise fullness and freedom, but have to deliver on that promise within the constraints of time, place, limited resource and user prioritisation. Now libraries are going digital, which is a leap forward in many ways, not least because it is much more frequently the case that they can say 'yes' than that they have to say 'wait'. For users, digitally available equivalents of the material requested - book chapters, journal articles, exam papers, music recordings, etc - are a gem because they can be used immediately without the need to go to the library premises to fetch them, or (worse) to find that they are currently unavailable, and waiting is required. This allows the digital manifestations of works to promote Ranganathan's Fourth Law of Library Science: 'Save the time of the user'. ${ }^{1}$ Of course, not all library users are satisfied with using resources on-screen from their own study bedrooms or homes. Many, particularly in the arts and social sciences, hold firmly to the positive value of browsing and serendipity. One of the tasks, indeed, for the digital library, is the simulation of browsing books on a shelf.

The success of ejournals, however, has propelled the development of the digital library more than any other type of content. The acceptance of the ejournal on university campuses has spread now to most disciplines, and the rejoicing which has recently come from the academic community over Google Scholar ${ }^{2}$ has been largely due to their preference for instant access to an ejournal over a wait of a few days for a paper version to arrive from the interlibrary loan department. Digital content, in this area at least, is now highly valued, and needs its libraries just as much as did content in any previous format, and librarians have now accepted that the day has come and gone when they might have seen the use of the digital medium somehow constrained to material which was not relevant to their roles. All library services therefore now need to develop digital libraries, and a world of wonderful possibilities has opened up. Digital and communications technologies offer the prospect of overcoming some of the frustrating limits of library services based upon physical objects - time, speed, distance, and cost. But even as they do, they bring in frustrations of their own: lock-out; system crashes; data obsolescence and loss, vendor reliance, and cost.

\section{The arrival of portals}

Portals are a familiar landmark in the digital world. Like the shopping mall, or the superstore or the multiplex cinema, they offer a themed multiplicity of content. They attract people, encourage them to feel hungry, and offer a range of goods to satisfy appetites. They have hooks designed to draw users in, and to bring them back again. To be effective, a library portal - like any other - will have to present a variety of options designed to meet the desires of different types of user all within a small area of screen real estate. They must satisfy users seeking to do serious research, users seeking quick reference information, users seeking basic service information, users looking for visually appealing content, and users wishing to make contact with the organisation behind the portal. And common to every option which the portal must satisfy are some basic quality indicators: a fast, responsive service; good, clear navigation; accessible language; and design for usability and for the desires and expectations of the primary user group. 
The portal has to reassure users that they have come to the right place. It should give some instant recognition and relief, and some enjoyable content to a user on a journey from an idea of what they seek to the end-point of their enquiry. A portal is an orientation space, a place where a user metaphorically sits down for a few moments to take a breather, scan some notices, and plan what to do next; a place where resolution may occur, halfway between a decision already made and a decision which they could be persuaded to accept. In the physical world, the portal is much more like the foyer of a museum than that of most libraries. Museums have been better at giving their visitors orientation spaces than have libraries. Museums greet their visitors with cafés; they give them visually appealing tasters, guides to collections and details of tour schedules. Libraries have rather assumed a seriousness of purpose from the point of entry to the building, with the idea perhaps that users are so intent on pursuing their quest that they are uninterested in taking a breather and orienting themselves. What distinguishes a library from a museum is the depth of its content, and the private way in which that content is to be consumed and enjoyed - either within the walls of the library, or by being taken away and used by readers in their own time. Are portals perhaps too frivolous for organisations with such serious aims to pursue?

The answer, of course, is 'no'. Libraries need portals in the same way that their buildings need foyers. It may be inappropriate for academic libraries to seek to appeal for portal users using popular entertainment 'hooks' - celebrity pics and gossip, half-price sale offers and online gaming - but they are now liberated by digitisation to dangle images of their most precious manuscripts or to assemble online exhibitions based on themes or authors in which they are strong. Lorcan Dempsey considers this parallel between the physical and the virtual library portal in a recent article:

So, interestingly, as collections and services move to the network, we see a renewed emphasis on the library place as 'agora', as a social assembly space. Developments include major new building work which focuses on this social aspect and on the symbolic aspect of the library, a growing interest in the exhibition and display of special collections and rare materials, on redeveloping space for social learning and interaction, on the library as a neutral 'third place', and on information and research commons activities. ${ }^{3}$

Making a portal instantly gratifying is of course only going to go so far, especially for academic libraries. What is more important is the 'one-stop shop' function, what we might consider the depth to the service by which it delivers convenience, which is arguably what distinguishes a library portal from a simple library web site. Any site can of course call itself a portal, and the presence of even a single link makes the argument. But for our purposes it is helpful to think of portals as richly integrated and comprehensively representative resources which provide convenience, and save the time of the user. Portals must have both depth and breadth, to justify their claim on the title.

\section{University library portals: historical development}

Library portals have had a different evolution from the portals of most organisations, because an online library presence, certainly in the case of academic libraries, has been a reality since the early 1980s for most. That was the time when OPACs (Online Public Access Catalogues) made their mark, and they were presented to users via terminals in 
the public areas of library buildings. When the web came along, and in time the idea that every organisation should have a web site, libraries initially created sites which were little more than lists of library services, with links out to services which had web or telnet interfaces. Thus, in July 1996, the Edinburgh University Library web site looked like this:

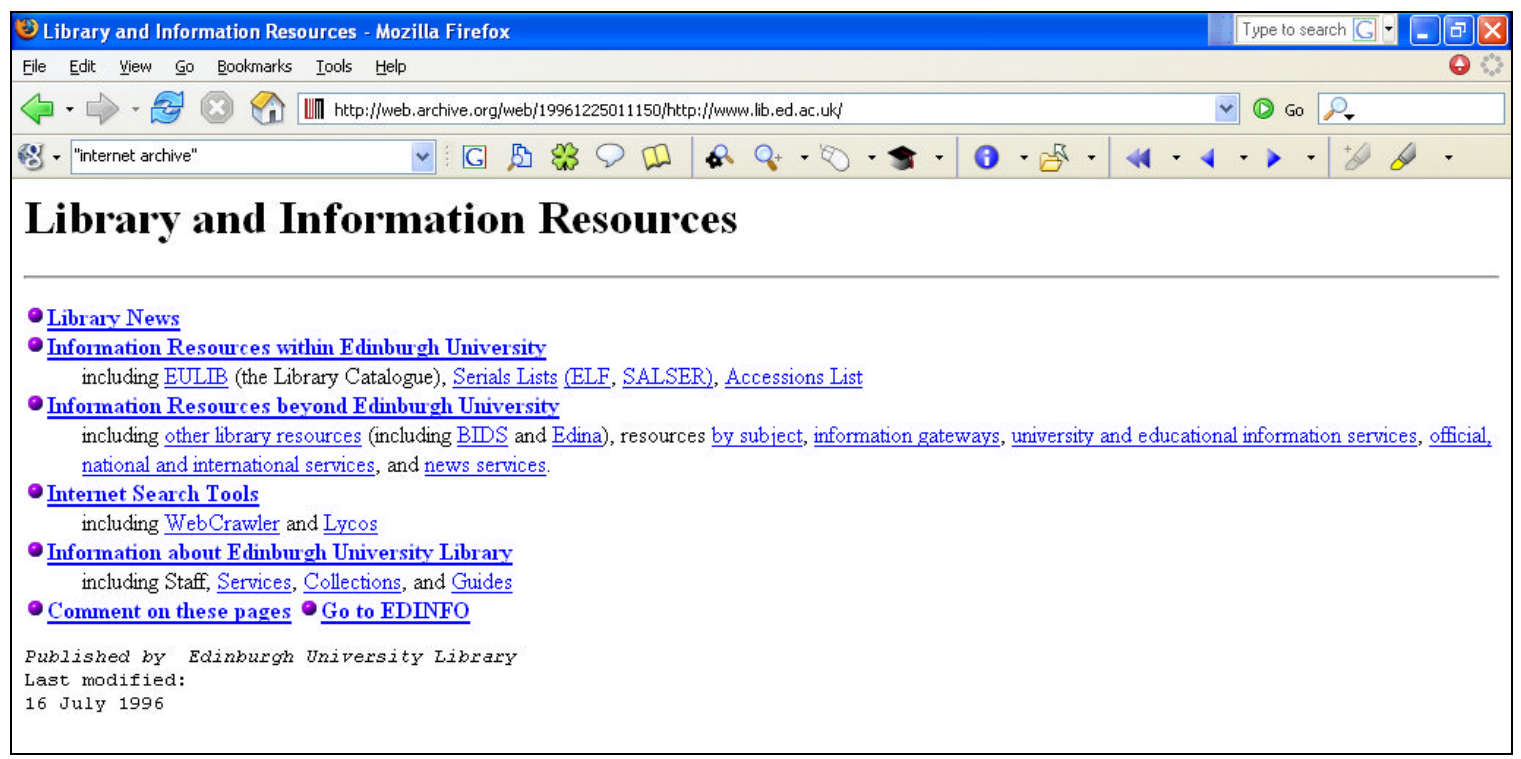

In this presentation, the Library catalogue ('EULIB') is just one among several services available via links. Clicking on the link opened a telnet session in a separate window. For most of the promised content, there is, in other words, no integration from one service to another beyond the presentation of meta-information. This is therefore simply a directorystyle web page. What prevents it justifying any claim to be a portal is that its convenience value claim - the collocation of links - is negated by the reality of following up on them. A collection of heterogeneous sites, with different interfaces, authentication demands and search vocabularies, represents a succession of barriers to the user.

Eighteen months later, the web site is presented slightly less crudely, with more resources available. Again, however, the library catalogue is not integrated, and the Library web site's purpose is to point to other useful resources, rather than itself to be one: 


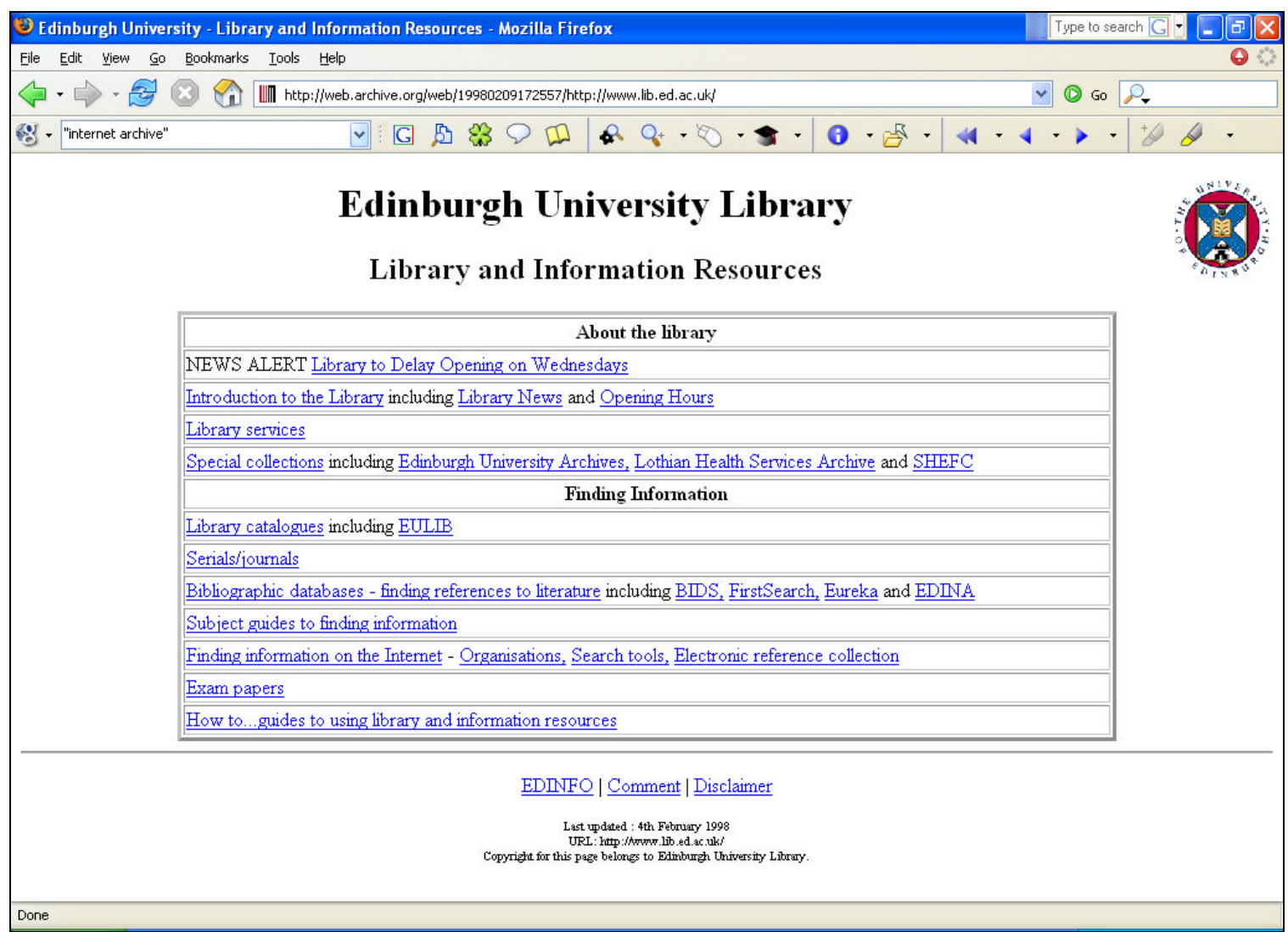

By May 2000, we find that the web site at last begins to pay some attention to design. The Library Catalogue option is not yet integrated, but it is at least available via a web interface: 


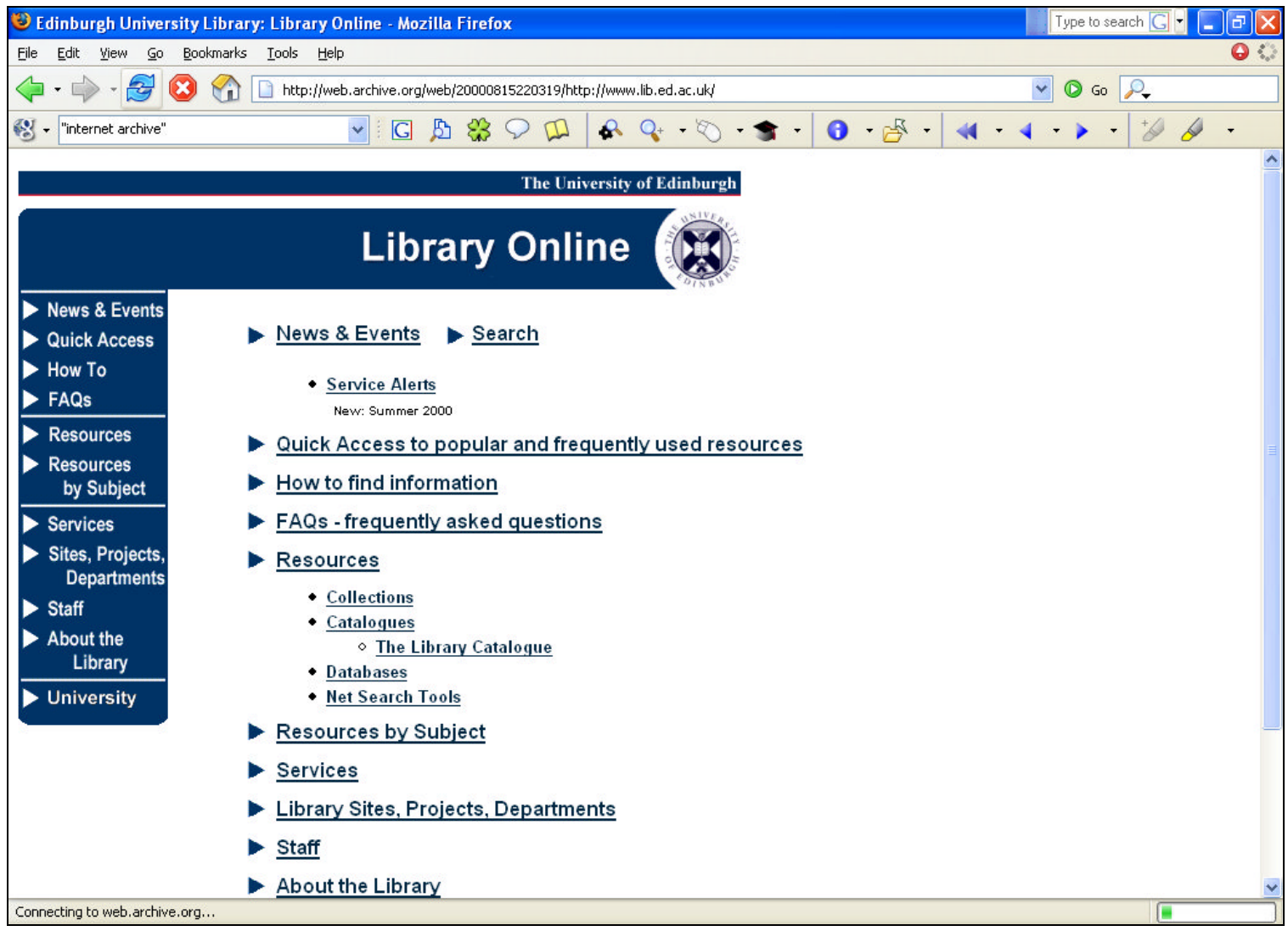

Today's site is slicker and better designed, but arguably not even yet properly a portal: 


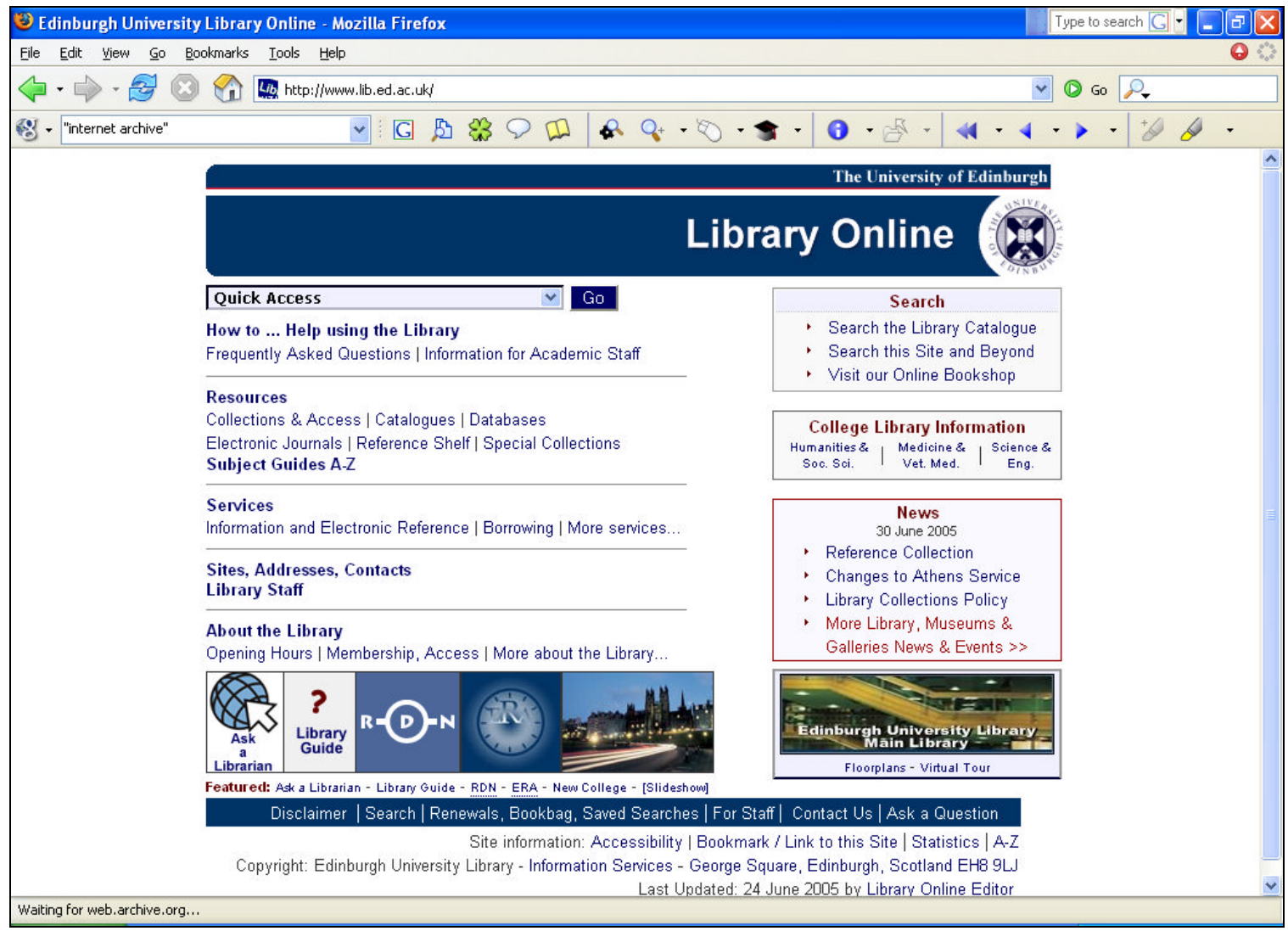

It offers the convenience of embedded searching in only one place, for a catalogue 'Quick Search':

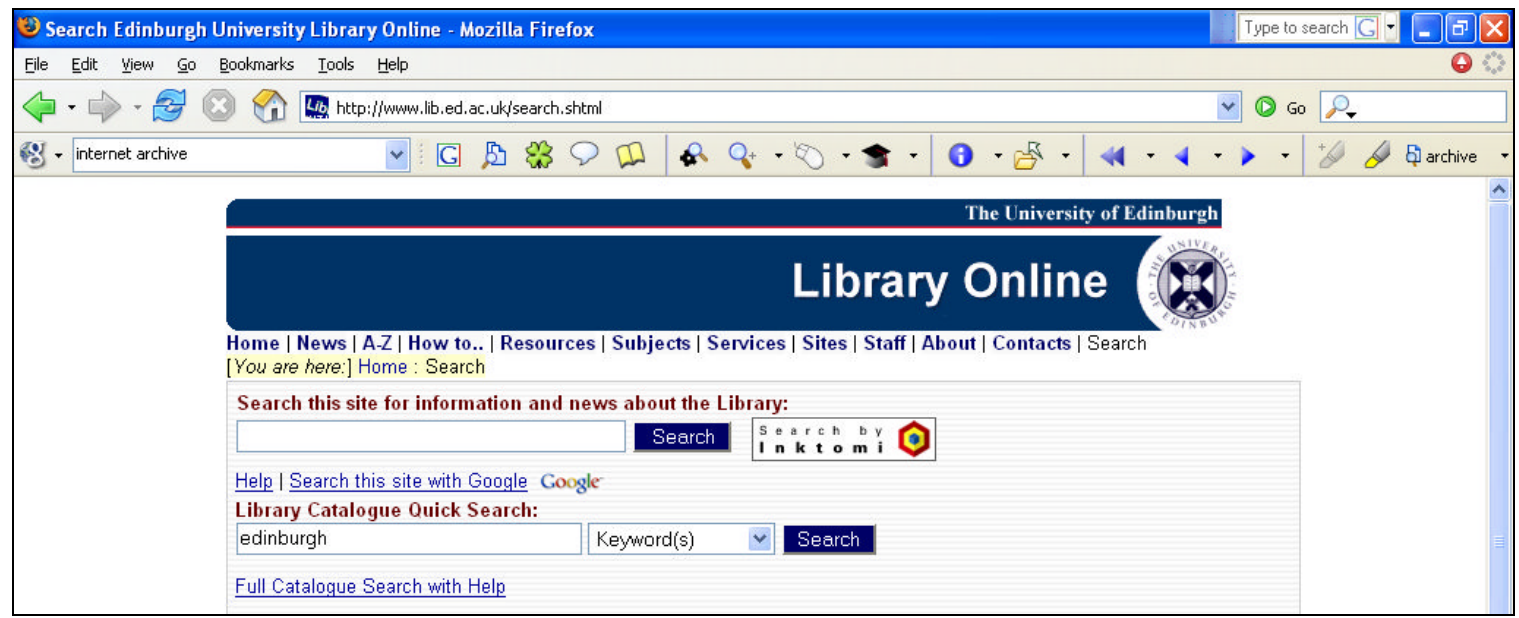

Edinburgh University Library, like many, has spent a lot of time considering the merits of introducing a separate library portal. Given the fact that most users of library web sites are in a tearing hurry to find a resource as quickly as possible, it has been argued that that a portal may not be worth the investment. Once a user finds a site via the library web site - whether it be a publisher's server, an open access repository, an online index, or any other service - and is happy with that site, their usual behaviour is to bookmark it so that 
they can find it the next time they need it, within the shortest possible timescale. On the other hand, we should not be too quick to presume that all users behave in the same way, and we do also need to present our services comprehensively for first-time or occasional users. We therefore continued with the development of our library web site, but have been hesitant about calling it a portal.

Recently there has been a real impetus to portal development however, as a new generation of search tools has appeared from library system vendors, based around the technologies of metasearch or harvesting, and in some cases providing a mix of both. These tools are designed to provide discovery functionality across the range of digital resources provided by libraries - both those held locally and those purchased under licence and held remotely by publishers or other aggregators. At the present time, the best known of these products is Metalib, by Ex Libris ${ }^{4}$, ENCompass by Endeavor ${ }^{5}$, Sirsi's SingleSearch ${ }^{6}$ and Innovative's Metafind ${ }^{7}$. Once installed, these tools are configured to work with their library's particular range of databases, and their whole objective is to offer 'one-stop shop' searching in order to save users time spent in discovering and aggregating results database by database, in learning different search interfaces, and in negotiating a succession of authentication and authorisation credential challenges. They are in effect portal creation toolkits, designed to fit the content provided by the digital library.

If libraries adopt these solutions, they are presented with a dilemma, because normally they will have a web site running separately, and will initially link to the metasearch service from the 'main' web site. Nevertheless, it soon becomes clear that the new service has in effect stolen a lot of the business of the web site, which had previously provided links to the range of services now capable of being metasearched. Should the web site now discard these links? Surely it would be better to rebuild the library web site around the metasearch portal? In short, we have arrived at a new juncture in the architectural development of academic digital libraries which is akin to the one we reached when we built our first library web sites and linked out to our separate telnet OPAC services.

A few leading libraries have understood the implications of this, and have already made the transition to a fully-fledged library portal, with a metasearch tool at its core (incorporating the OPAC). The University of Pittsburgh provides an example of this: 


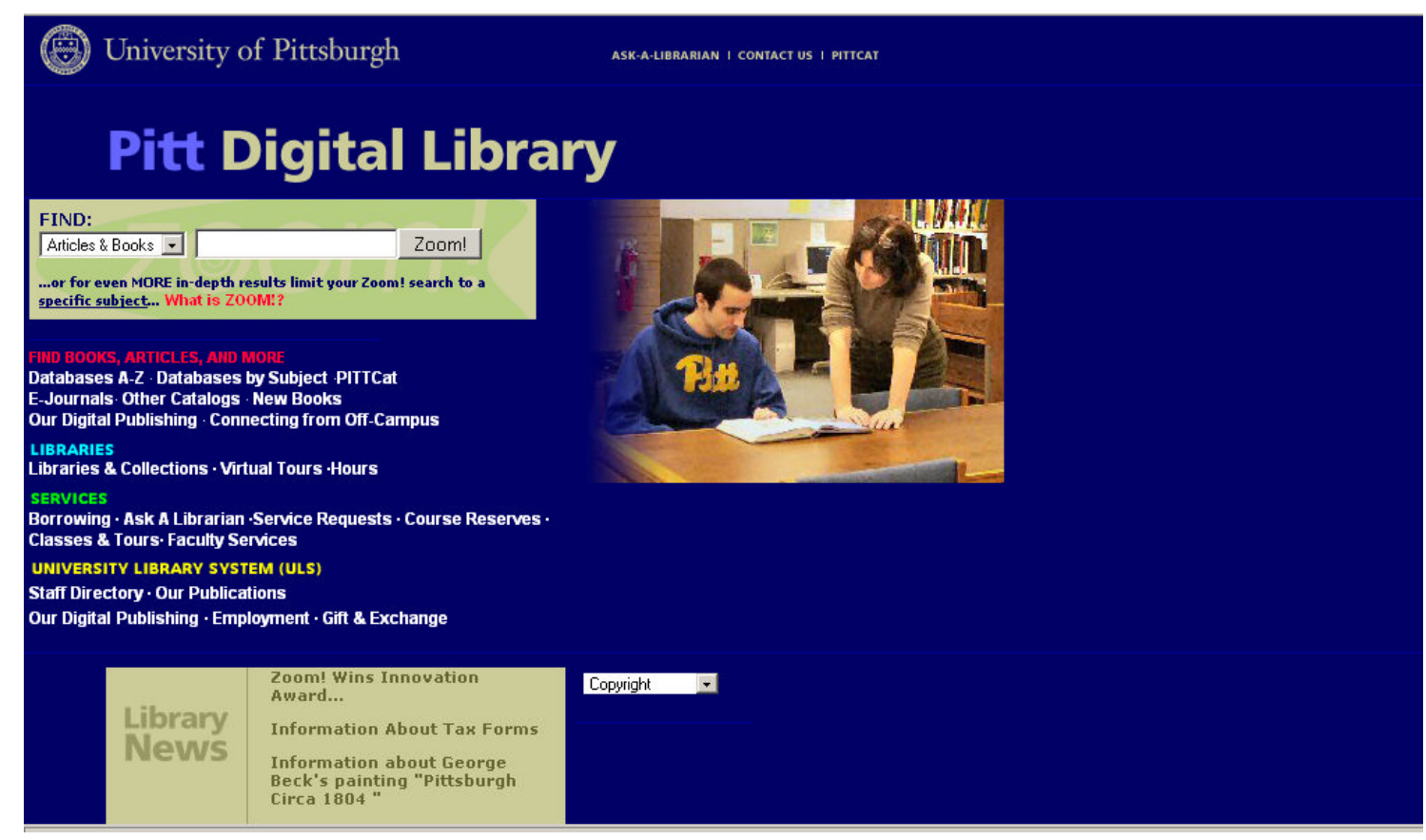

With a proper library portal now functioning, the digital library has arrived at the equivalent of the central campus library building, concentrating a range of services into a single point, and standing ready to serve all comers.

Yet, as with the central library building, what libraries have found almost at the same moment is that the 'centralised' portal is not enough for its user community. Academic staff love to have their own departmental libraries just down the corridor. They value having their own dedicated, specialist library staff. They like to be able to send their research assistants along to pick up their interlibrary loan photocopies, or to borrow books in their name. They want a key which will let them into the library in the middle of the night if, during an experiment, they have an urgent need to check back to a paper published some time ago. What they want, in fact, is a bespoke library, customised around their own needs. They do not want the authoritarian attitude of the central library, with its stern rules about not borrowing journals, its fixed opening and closing times, and its unfamiliar staff who are ignorant of their disciplines. It may offer an impressive range of services, but they only need two or three of them, provided they are of top quality. The central library is still very important - for the undergraduate community in particular - at least as long as most learning materials are still physical objects, and as a back-up facility for the entire service. But researchers find that their time is more effectively used with specialist library satellites.

Undergraduates, too, are increasingly liberated from the pressure to study on the library premises through the wide use of VLEs (virtual learning environments). As elements of those environments are unbundled and presented within a portal which represents their own experience of the university, so the library is similarly pressured to deliver content to a single customisable portal at the campus level. 


\section{Customisable portals}

It is for that reason that the customisable portal which is now appearing on university campuses may fit the requirements of many library users better than either the centralised portal or its predecessors. Portals which can be personalised to the range of campus services relevant to or desired by individual members of the university are now being developed through systems like JA-SIG's uPortal ${ }^{8}$. They offer a default set of services which are either native to the portal, or 'channelled in' from other parts of the campus web architecture, including, of course, the library. These channelled services together compose the bespoke portal, and are known as 'portlets'. Users can choose which channels to retain and which to discard. The technology of the personalised portal is still somewhat clunky and imprecise, and the organisational arrangements on campuses to build them and maintain them are having to be developed on the ground, with a great deal of difficult liaison effort.

The University of Edinburgh recently released its customisable portal - MyEd - which incorporates a library channel and looks like this:

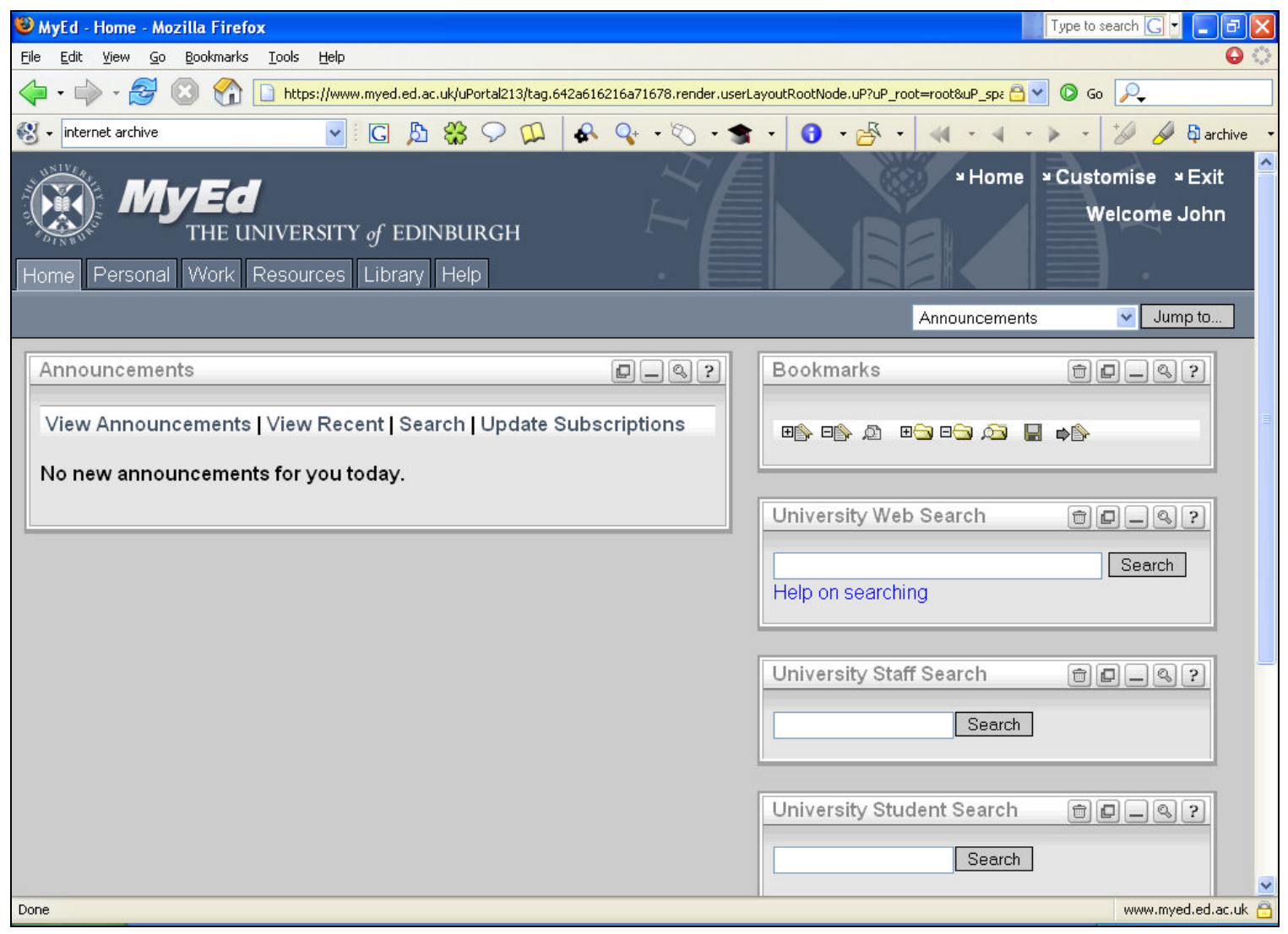

The library channel is not yet ideal, offering a selective subset of services and functions which are determined more by what is technically possible rather than by what is ideal for delivery to personalised portal users. Again, this stage of development is reminiscent of library web sites of 10 years ago, which provided links to other services on the internet on 
the basis of what was available rather than what was desirable. Its presentation at present requires the user to scroll down through three screens, as shown here.

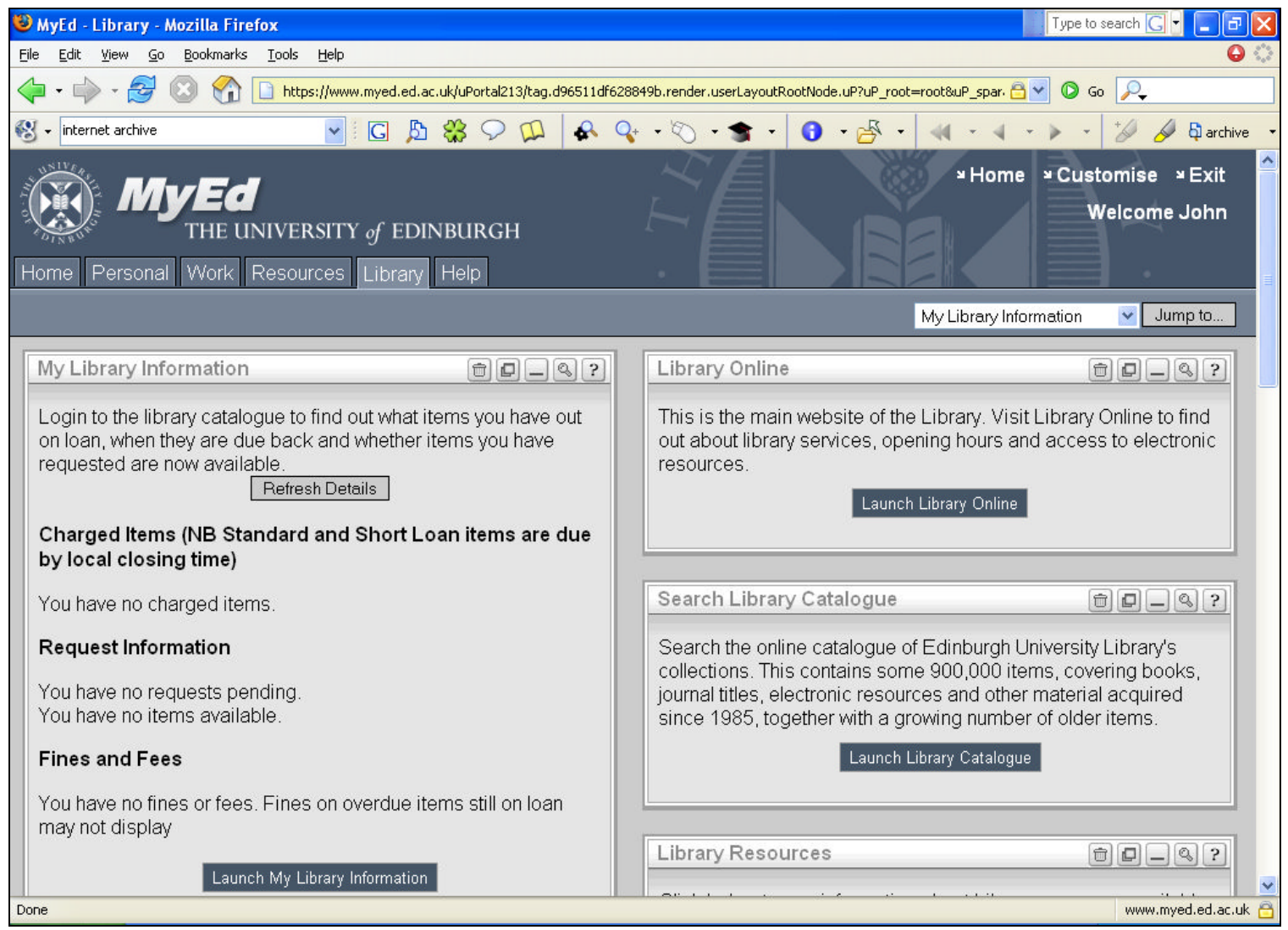




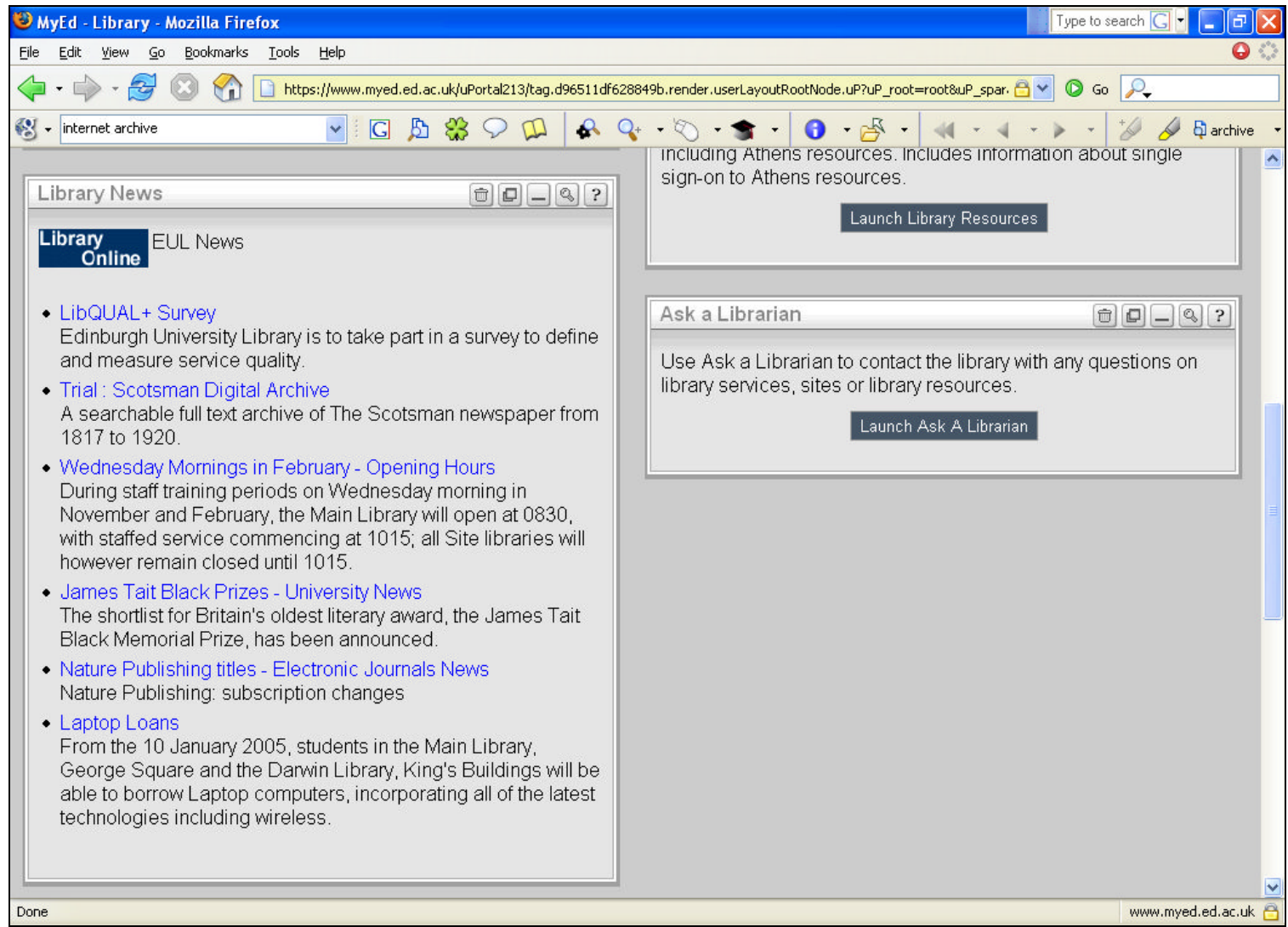

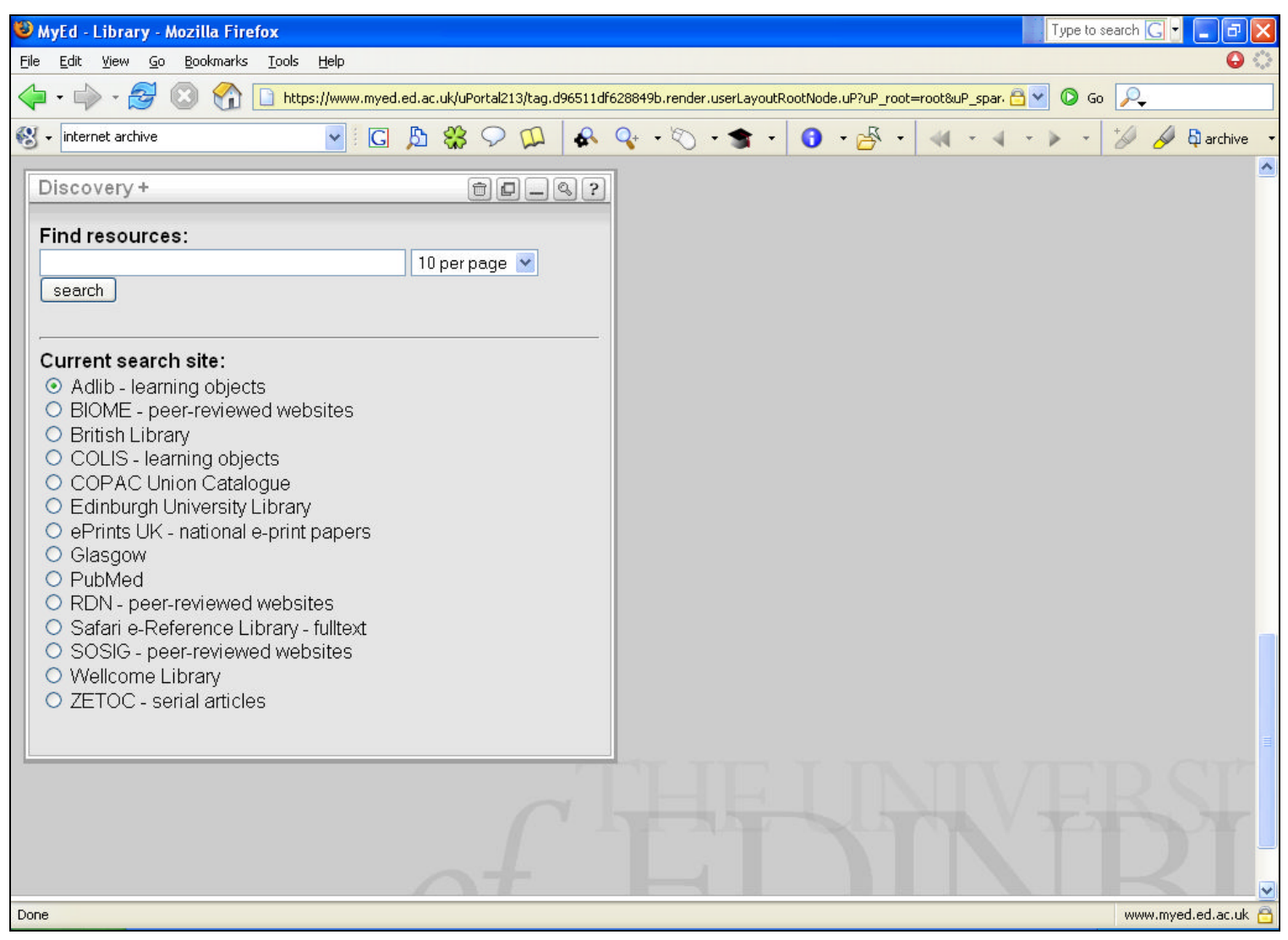


It is also clear that this portal does not yet offer maximum convenience: most of its services are not truly integrated. The majority of them require to be 'launched' from the portal, which is simply a way of providing links to them. True portalised integration brings the search functionality into the portal, allowing the user to remain in the portal while having their various needs met. MyEd's library pages achieve this at the present time only for the 'Find Resources' service.

\section{Integration and portals}

In his article on library portalisation, Lorcan Dempsey discusses integration in terms of shallowness and depth:

In the first case, a resource is made available at, say, a web page. The intended consumer is a human, so it is oriented towards reading and navigation. Integration of resource content needs to be provided by the user. Think of the user who successively looks at several catalogs: typically, he or she will have to manually integrate, sift, manipulate or merge. Most of our information services are now made available in this way. Think of the library 'portal' which provides organized lists of internet resources. The user may be guided to resources of interest, but once they commit to looking at a particular resource, they leave the 'portal' environment and are delivered to the door of the remote resource. Think of lists of e-journals, or of abstracting and indexing databases: again, the user may be guided, may have a personalized list of resources presented to them, but is then delivered to the front door of the desired resource. Once they go through the door of the desired resource, the user is in that remote resource environment, and needs to behave appropriately. The desired resource sits on the network behind its own user interface. Integration is shallow. ${ }^{9}$

Many such portals at the present time deliver the experience of 'integration failure'. It can be difficult to spot unintegrated portal services, because portals by definition make bold claims of integration for themselves. Seeking to provide "sticky content' ${ }^{\text {'0 }}$ they wish to take credit for integration when often all they are providing is collocation. As users become more savvy, however, they will not be fooled, and both libraries and their institutions need to be careful not to oversell their portal offerings. Savvy users, once disappointed, will often not return.

Some sites have already developed reasonably advanced integration, such as can be seen in the University of Nottingham's portal, which is also based on the uPortal platform: 


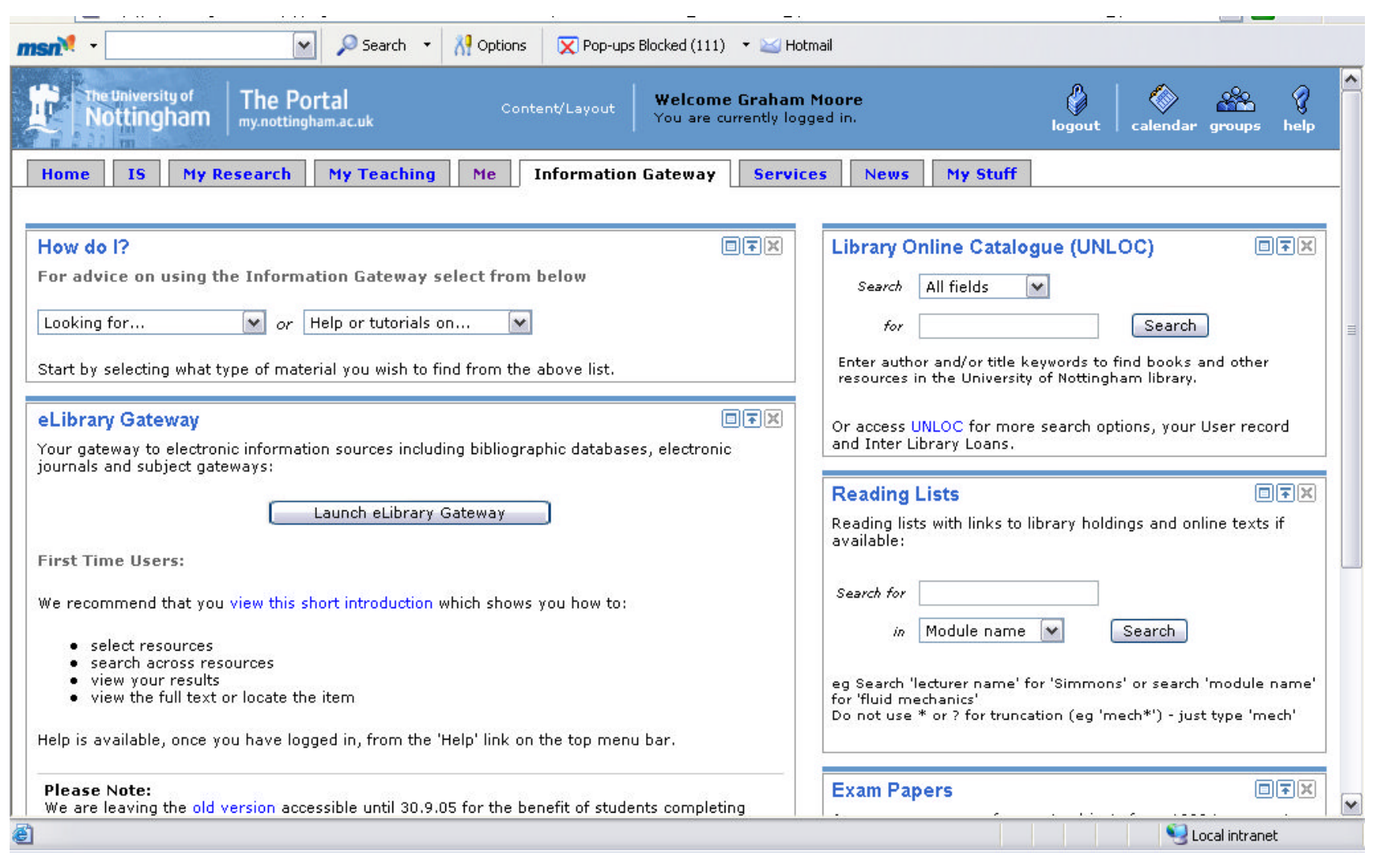

Here, the integration is almost complete, though the 'eLibrary Gateway' remains a challenge. Such integration is achieved by the machinery of the portal, rather than by a simple collocation of links which remove the user to remote environments. Dempsey considers that this level of integration makes a portal into a 'broker':

A broker provides a deeper level of integration. Here are examples of what broker applications do:

- hide difference and the mechanics of interaction from users, so as to save time and simplify procedures. An example here would be a cross-searching application which creates a federated resource from several others. Of course, such applications raise various complications in implementation.

- facilitate flow of data between applications so as to automate processes. This includes interapplication integration. An example here would be a resource sharing application which mediates searching, ILL, resolution, and document delivery transactions, perhaps interfacing with billing or other applications.

- aggregate resources for further use. An example here would be an OAI-PMH-based harvester which takes data from several sources and makes it available at a machine or a user interface. The Open Archives Initative Protocol for Metadata Harvesting is a technique for sharing metadata between services. One service - a data provider in OAI terms - makes metadata available in an agreed way; another service comes and 'harvests' it. The latter service - a service provider in OAI terms - may harvest from multiple 'data providers' and in turn may provide access to the metadata it collects in this way. ${ }^{11}$ 


\section{Conclusion}

At the present time, the degree of brokerage which Dempsey describes is hard to find on university portal sites, whether library portals or institution-wide portals, either personalisable or not. But there is progress towards it. The library channel in the 'MyEd' Edinburgh portal described above deploys harvesting, for example, and our ability to deliver search results from different types of database - OPACs, databases of exam papers or of reading lists - is growing, as we convert data structures to XML and build web services into our sites. We have some distance to go to achieve the sort of portalisation technology which makes the top commercial services on the web, such as amazon.com, so successful, and of course we have lacked the commercial imperatives to develop our portals to that extent.

Nevertheless, we do need to do this development. Academic libraries feel threatened at the present time almost to the point of paranoia. There can seem to be so many challenges to our business that we are not sure who to be most threatened by, and whose threat is the greatest. Google and amazon are threats from outwith the university; institutional portals can seem like threats from within it. But the only real threat comes from services which provide pseudo results - references and documents - which are not based on good retrieval algorithms and which provide easy material, or material which has a hidden agenda (such as linkage to advertisements), rather than quality controlled content. A library, as Ross Atkinson noted in an article published in The Library Quarterly in 1996, is a controlled environment (what he calls a 'control zone'). ${ }^{12}$ While its content, now digital or with digital proxies in the form of metadata, may be and should be 'unbundlable' and resurfaceable, in portlet form, within other portals such as those which present the whole campus experience, there is still a strong reason to keep it also bundled and assembled, to provide a full picture of the quality controlled content which represents the sum of its collections, designed around its various user groups. The only comprehensive way to do that now is to do it digitally, and so the development of an effective, fully integrated academic library portal is a task of the utmost importance. Though its buildings and its physical objects are still essential, the library portal is now the only means now available to represent the library in its entirety. Building it well and ensuring that it meets the needs of our users is one of the highest priorities for academic libraries at the present time.

\footnotetext{
Ranganathan, S. R., (1931) The five laws of library science (London: The Madras Library Association) See http://scholar.google.com/

Dempsey, Lorcan (2003) 'The Recombinant Library: Portals and People.' Co-published simultaneously in Journal of Library Administration, 39,4:103-136; and in Improved Access to Information: Portals, Content Selection, and Digital Information, ed. Sul H. Lee, 103-136. Binghamton, NY: Haworth. Available online at: http://www.oclc.org/research/staff/dempsey/recombinant_library/

See http://www.exlibrisgroup.com/metalib.htm

See http://encompass.endinfosys.com/

See http://www.sirsi.com/Solutions/Prodserv/Products/singlesearch.html
} 
7 See http://www.iii.com/mill/digital.shtml\#metafind

8 See http://www.uportal.org/

9 Dempsey, Lorcan (2003) 'The Recombinant Library: Portals and People.' Co-published simultaneously in Journal of Library Administration, 39,4:103-136; and in Improved Access to Information: Portals, Content Selection, and Digital Information, ed. Sul H. Lee, 103-136. Binghamton, NY: Haworth.

Available online at: http://www.oclc.org/research/staff/dempsey/recombinant_library/

10 'Sticky content' is a phrase which has been around since the late 1990s. See a definition at http://www.realdictionary.com/computer/Computer/sticky-content.asp

11 Dempsey, Lorcan (2003) 'The Recombinant Library: Portals and People.' Co-published simultaneously in Journal of Library Administration, 39,4:103-136; and in Improved Access to Information: Portals, Content Selection, and Digital Information, ed. Sul H. Lee, 103-136. Binghamton, NY: Haworth. Available online at: http://www.oclc.org/research/staff/dempsey/recombinant_library/

12 Atkinson, Ross (1996) 'Library functions, scholarly communication, and the foundation of the digital library: laying claim to the Control Zone', The Library Quarterly 66 (3) 239-265 